\title{
The Social Interpretation of Language and Meaning
}

\author{
Ming Liu \\ The Department of Foreign Languages, Nanchang Normal University, Nanchang, China
}

\begin{abstract}
Systemic Functional Linguistics provides a social perspective to language study and views language as a social semiotic resource people use to accomplish their purposes by expressing meanings in context. This paper aims to discuss the semantic aspect from the three metafunctions and the context in which meaning is realized.
\end{abstract}

Index Terms-functions, context, meaning

\section{INTRODUCTION}

Systemic Functional Linguistics (SFL) provides a social perspective to language study and regards language as a social semiotic resource. People can use it to accomplish their purposes by expressing meanings in context. SFL is a function-oriented linguistic theory which permits the study of language in social and cultural context, and then it has developed register theory based on the 'context' put forward by Malinowski. The social interpretation of language and meaning will be briefly discussed in this paper.

\section{SEMANTIC DivERSIFICATION}

People make their own different objectives accomplished by means of language. It is known that people can use language resources to reveal inner and outer experience around the world. Language is an important way to convey what happens around them and inside them. Jakobson, in his famous article, Linguistics and Poetics, established a famous framework of language functions which includes six key functions, that is referential, poetic, emotive, conative, phatic and metalingual function. However, Halliday identifies three metafunctions, the ideational, the interpersonal, and the textual. And he once stated "all languages are organized around two main kinds of meaning, the 'ideational' or reflective, and the 'interpersonal' or active" and "combined with these is a third metafunctional component, the 'textual', which breathes relevance into the other two" (Halliday, 1994, p.39). In the functional model of SFL, the ideational, interpersonal and textual functions consist of three orientations to language, which exist simultaneously in every levels of language. The three functions of language are realized with their own subsystems and in turn these subsystems (transitivity, mood, evaluation, thematic structure, information structure, cohesion system) are composed of multi-parameters for linguistic analyses in a particular discourse.

The ideational metafunction is concerned with ideation. Ideation is mainly concerned with content or proposition of message. This kind of metafunction can be further classified into the experiential and the logical types. "Experiential meaning is expressed through the system of transitivity or process type, with the choice of process implicating associated participants roles and configurations" (Eggins, 2004, p.206). Transitivity is the representation in language of processes, the participants and the circumstantial elements associated with them. The meaning of transitivity refers to the language characteristics of the clause which embody the speaker's or writer's experience or something else in the world, not the narrower meaning as in "transitive and intransitive verbs". The term is used in line with 'mood' and 'theme' which convey respectively textual and interpersonal function. The transitivity system of a language aims to construct people's experience into the meanings which differ in the following two aspects: the process itself and the nature of the participants involved in it. The interpersonal metafunction is concerned with the interaction between speaker and addressee(s), through which they express their own attitudes and judgments or attempt to influence other's attitudes and judgments. In other words, the interpersonal meaning is construed with clause as exchange. The clause shows the speech roles in an interaction, in which giving implies receiving whereas demanding has the implication of giving in response. The textual metafunction is concerned with the creation of text, which is mainly about how to get a text characterizing coherence. The theory that specifically deals with the ways of how messages are organized is technically called textual function, which is mainly composed of three subtypes of semantic systems: thematic system, information structure and cohesion system. The thematic organization that concerns with the way of how message is conveyed consists of two functional components: Theme refers to a point of departure for the message and Rheme new information about the point of departure. The definition of Theme as given by Halliday and Matthissen (2004, p.64) is that it is the element which serves as 'the staring-point for the message: it is what the clause is going to be about'. In English Theme is easy to be recognized for it often comes first in the clause. Halliday (1994, p.37) categorizes the 
remainder of the message, the part in which the Theme is developed, into the Rheme. Rheme combines with Theme to form a clause, which expresses a complete meaning from the textual organization.

Thompson summarizes the three kinds of meaning of metafunction in a simple language as follows: "We use language to talk about our experience of the world, including the worlds in our own minds, to describe events and status and the entities involved in them; we also use language to interact with other people, to establish and maintain relations with them, to influence their behavior, to express our own viewpoint on things in the world, and to elicit or change their; finally, in using language, we organize our messages in ways which indicate how they fit in with the other messages around them and with the wider context in which we are talking or writing" (1996, p.28).

Metafunctions are not to be seen as functions in the sense of 'uses of language', but as functional components of a semiotic system. They are modes of meaning which are present in every use of language. The metafunctional simultaneity is manifested as three simultaneous strands or layers in the structure of the clause, which respectively construes different meanings in the physical world as well as mental world.

\section{CONTEXT}

SFL views language as a social semiotic resource people use to accomplish their purposes by expressing meanings in context. In the original sense, context refers to the sentences and the texts that came after and before other sentences and texts. But in modern linguistics, the meaning of context has been extended to the nonverbal environment, in which communication takes place and physical activities are going on.

The theory of context is formed with contributions chiefly from B. Malinowski, J.R. Firth, and M.A.K. Halliday. Context is a key conception in SFL, which is classified into two types: 'context of situation' and 'context of culture'. Context of situation was firstly used by Malinowski in the sense of actions that are happening when participants speak, and then developed by Firth who treated situation as a linguistic context. Firth was concerned with the generalized actual, which led him the framework. The framework contains four contextual factors: "the participants in the situation, the action of the participants, other relevant features of the situation, and the effects of the verbal action" (Martin, 1992, p.497). The framework was developed into the concept register. Register is defined as "the configuration of semantic resources that the member of the culture associates with a situation type and is the meaning potential that is accessible in a given social context" (Halliday, 1978, p.111). Register is a useful term to relate the linguistic elements with nondiscursive ones. This thesis will use it to discuss the linguistic realization of discursive hegemony, through which the social structure can be uncovered. So register will be explained in the following chapters along with discursive hegemony.

In addition, Martin (1992, p.493) not only has explored the concept 'context' from the perspective of language itself, but also investigated it from the perspective of culture. Seen from the former, context is interpreted as reflecting semantic diversification while seen from the latter, context as a system of social processes. Martin proclaimed that these two explanations of context are based on two communication planes, register (context of situation) and genre (context of culture). He especially emphasized that "register functioning as the expression form of genre, at the same time as language functions as the expression form of register" (1992, p.495). Language, register and genre constitute a contextual model.

Genre is a term widely used in plenty of disciplines, such literary studies as the Bakhtin's works. A genre for Bakhtin is the language used in a particular form of activity, and it is characterized by a particular thematic content, a particular style and a particular compositional structure (Bakhtin 1986). For Martin and Rose, a genre is "a staged, goal-oriented social process" (2003, p.7). Genre, in Fairclough (2003, p. 65), is defined as "the specifically discoursal aspect of ways of acting and interaction in the course of social events." From those definitions, 'genre', which orients to social activity and social change, possesses the traces left by social change and the struggle for hegemony. It is worth to mention that there is no established terminology for genres. Eggins recognized a series of different genres in English culture, which include "literary genres, popular fiction genres, popular non-fiction genres, and educational genres" (2004, p.56). And he also claimed there is an extensive range of everyday genres, genres in which we take part in daily life, such as: buying and selling things, seeking and supplying information, telling stories, gossiping, making appointments, exchanging opinions, going to interviews, and chatting with friends (Eggins, 2004, p.56). However, on the basis of different levels of abstraction, Fairclough classified genres into three main types: "pre-genres, disembedded genres, and situated genres" (2003, p.68). In a word, social context is divided into levels of genre and register, which have to be grounded in language. Language, register, and genre form a stratified context plane.

Genre (as context of culture) is realized as register (as context of situation), which is in turn realized as language. Register is organized with respect to field, tenor and mode, reflecting semantic diversity, which refers to metafunctions of language. Besides, variables of register do not have one-one correspondence with three functions of language. In the whole, language acts as the expression form of register while genre is related to social processes which are the sites of social struggle and of social change. "Access to genre, register and language as semiotic resources", according to Martin (1992, p.495), is "mediated through discourse of ethnicity, class, gender and generation, which discourses are in a continual process of negotiation with each other". Therefore it is beneficial to investigate discursive hegemony by means of those three semiotic resources with respect to the dimension of discourse. 


\section{THE SOCIAL INTERPRETATION OF LANGUAGE AND MEANING}

In the previous section, we have explored the relation between language and context. Language used in social context should be broadly investigated in terms of a social perspective, which mainly deals with language as a social behavior, rather than as knowledge. Taking language as knowledge, which is psychophysiological or cognitive perspective, tends to explore what goes on inside the individual's head. The view attempts to find out the working mechanisms of the human brain in speaking and understanding.

In general, there are two broad orientations in modern linguistics. One is formalist (structuralist, generativist) perspective, which views a central task for linguists characterizing the formal relationships among grammatical elements independent of any semantic or pragmatic factors of these elements. To the classic formalist, language is a closed system which has to be described and explained from within. The other orientation to language study is functionalist perspective, which, however, holds that language should be investigated under the broad framework that includes semantic and pragmatic properties of grammatical elements, personal and social factors in the particular description or explanation of certain words or utterances. The functional approach, which centers on linguistic explanation based on language's function in a larger context, has recently come to associate with Halliday and other functionalists.

SFL views language as a social semiotic resource people use to accomplish their purposes by expressing meanings in context. Systemic theory is a theory of meaning as choice, by which a language, or any other semiotic system, is interpreted as networks of interlocking options (Halliday, 1994, p.40). In any context, there are a lot of meanings that speakers might convey, and a lot of ways that they might use to embody them. Language is seen as a system of systems" The system network is a theory about language as a resource for making meaning. Eggins (2004, p.190) defines the linguistic system in terms of syntagmatic relations and paradigmatic relations.

Thompson has at several points used term 'choice' in discussing meanings. The idea of choice that speaker/writer has multiple ways to express what they want to convey in a given situation has permeated in many works related to SFL (1996, p.8). Language realized in actual utterance by language users is a result of choices among a number of possible ways to express the meanings they want to communicate. Halliday argues that "language is a resource for making, an indefinitely expandable source of meaning potential" (1994, p.16). This view of language as a system has the implication that language is not a well defined system, not the set of all grammatical sentences. It also implies that language exists and therefore must be studied in context. The available choices depend on aspects of the context in which the language is being used. Since language is viewed as semiotic potential, the description of language is a description of choice.

Halliday drew the distinction between the two perspectives to language by using a pair of terminology — interorganism and intra-organism' (1978, p.12). Speaking and understanding language in a context takes the inter-organism perspective. Although the two perspectives form a complementary relation, the thesis takes the social perspective to language for the objective of this thesis. So the following lines will briefly discuss the explanatory linguistic theory for revealing nondiscoursal elements from language itself, which is enlightenment to the current study.

The study of language as social behavior is to account for language choice which is also technologically called 'meaning potential'. Halliday regarded language as "the encoding of a 'behavior potential' into a meaning potential" (1978, p.21). And he respectively used 'can do' and 'can mean' to refer to behavior potential and meaning potential. What we 'can mean' is one expression form of what we 'can do', which is viewed as semiotic system and can be encoded in language. Of course, what we 'can do' has other expression forms, such as non-verbal language, visual image, including such coercive means as police, army, economical policy and so on. But language is still the main expression form of what we 'can do'. Participants in communication can use language to simultaneously perform three functions, which are analyzed at the grammatical level. But in order to get a good understanding the functions of language, we, language users or researchers, should go outside the language, and see language itself as the realization of something beyond, which, in Hallidayan words, refers to what we 'can do' or behavior potential. Therefore, it is of necessity to explore and interpret the meaning of language in social context from the social perspective. The concept of social context is defined as: "a generalized type of situation that is itself significant in terms of the categories and concepts of some social theory. The theory may focus attention on different facets of the social structure: not only on forms of socialization and cultural transmission, but also on role relationships, on the power structure and patterns of social control, on symbolic systems, systems of values, of public knowledge and the like" (Halliday, 1973, p.63).

These quoted words from Halliday provide us with a good window through which we can clearly see the significance of social perspective to language. From the socio-semantic perspective, the interpretation of language in social context in Hallidayan linguistic model is closely related with that of Bernstein's sociology. Bernstein's sociological theory has influenced developments within SFL. Bernstein's interest has been in the role of language in socialization. Language is concerned with something which both influences culture and is in turn influenced by culture, with the second influence apparently stronger than the first. The dialectical relation language and culture can be obviously seen from the words of Bernstein himself: "the form of the social relation or, more generally, the social structure generates distinct linguistic forms or codes and theses codes essentially transmit the culture and so constrain behavior " (Halliday, 1978, p.24). A unique feature of Bernstein's illustration is that it suggests how the social structure is represented in linguistic forms or codes, which are carved into two types: elaborated code and restricted code. An idealized interlocutor in conversation or 
communication would have equal access to all varieties of code. However, in fact, in the processes of socialization it is not the fact that everyone has the same access all linguistic forms or codes. Every one as a social man has to experience the processes of socialization, such as the progression of children's language from family to school. Analyzing the changes of language spoken by children can effectively show that of social position held by children, even that of social structure. For instance, children from the lower working family are likely to find themselves at a disadvantage when they attend school because they lack of those code system hold by other children. Language is intricately interwoven with social factors, such as class, ideology, power.

Language is concerned with such social factors as context of situation. A particular choice in language system may be appropriate or inappropriate to a given context. The appropriateness or inappropriateness is related with another characteristic of language, which is commonly shared by most systemic linguists. Although individual scholars naturally have different research emphases or application contexts, the common interest is the opinion that language is seen as social semiotic, which means "how people use language with each other in accomplishing everyday social life" (Eggins, 2004, p.3).

It is proper to say that language system is the most sophisticated of all semiotic system, because language system has the feature of duality which is absent in other semiotic systems, such as traffic lights. Through language we, human beings, can perform various social roles, which are determined and constrained by lots of social factors rather than only speech roles of language communication. Unlike formalists who regard language as an independent system, SFL takes language as a social semiotic resource people use to accomplish their purposes by expressing meanings in context. The term 'context' playing a key role in SFL is classified into two types: 'context of situation' and 'context of culture'. Halliday treats the 'situation' as "the theoretical sociolinguistic construct", and a 'particular situational type' as a "semiotic structure". The semiotic structure of a situation type is represented as follows:

The semiotic structure of the situation is formed out of the three sociosemiotic variables of field, tenor and mode. These represent in systematic form the type of activity in which text has significant function (field), the status and role relationships involved (tenor) and the symbolic mode and rhetorical channels that are adopted (Hallidy, 1978, p. 122).

According to Halliday, the text is specified and determined by field, tenor and mode, usually called 'three variables of register'. A register is a set of meaning potential in a given social context and is more abstract than the immediate situational factors, such as time and space. Register, which however is less abstract than social structure, mediates between discourse and social structure. In other words, social structure is realized as register, which in turn is realized as discourse. Social structure has its own forms of discursive realization through field, tenor and mode. In this sense, the social factors that have impact on discursive hegemony can be uncovered with the help of register.

Although a large number of scholars have dedicated a lot to the field of text analysis and has proposed many new viewpoints and analytical framework, text analysis has not reached overall agreements on the points of theory and practice of text analysis. Gee (1999, p.5) proposes that "people with different theories about a domain will use different methods for their research." Six approaches to text analysis have been introduced by Shiffrin (1994). SFL, which explores language in use, provides a new linguistic framework for the approaches to text.

As Halliday points out, one of the aims of his construction of systemic functional theory is: "to construct a grammar for purposes of text analysis: one that would make it possible to say sensible and useful things about any text, spoken or written, in modern English" (Halliday, 1994, p.41). He enumerates 21 purposes for which linguistics is likely to be useful. And Huang (2006) also points out that his systemic functional theory is "appliable linguistics", and the existing literature shows that this theory has been applied to studies of texts, both spoken and written in modern languages.

As a functional-semantic approach to language, there are many different purposes for which one may want to analyze a text. SFL has been used as a theoretical framework for analyzing text of many types, from literary works such as novels, plays, poems to non-literary texts such as advertisements and business letters. As an appliable linguistics theory, it has been used in more specific and particular tasks such as the study of the language of textbooks, stylistic analysis of poems. In this thesis, we will use SFL as a linguistic tool to analyze the implicit meanings embedded in discourse with variety of hegemonic factors.

\section{CONCLUSION}

SFL theory uses language as a social semiotic resource people use to accomplish their purposes by expressing meanings in context. The metafunctional simultaneity is manifested as three simultaneous strands or layers in the structure of the clause, which respectively construes different meanings. That is to say, language is rich and multifaceted. People construe meanings in three aspects at the same time, which embodies the social significance of language.

\section{REFERENCES}

[1] Bakhtin,M. (1986). Speech Genres and Other Late Essays. Austin: Texas University Press.

[2] Eggins, S. (2004). An Introduction to Systemic Functional Linguistics (2nd edn). London: Continuum.

[3] Fairclough, N. (2003). Analysing Discourse: Textual Analysis for Social Research. London and New York: Rouledge.

[4] Gee, J. P. (1999). An Introduction to Discourse Analysis: Theory and Method. London: Rouledge.

[5] Halliday, M.A.K. (1973). Explorations in the Functions of Language. London: Edward Arnold. 
[6] Halliday, M.A.K. (1978). Language as Social Semiotic: The Social Interpretation of Language and Meaning. London: Edward Arnold.

[7] Halliday, M. A. K. (1994). An Introduction to Functional Grammar (2nd edn). London: Edward Arnold.

[8] Martin, J. R. (1992). English Text: System and Structure. Amsterdam and Philadelphia: Benjamins.

[9] Thompson, G. (1996). Introducing Functional Grammar. London: Edward Arnold.

[10] Schiffrin, D. (1994). Approaches to Discourse Analysis. Oxford: Blackwell.

Ming Liu was born in Jinxian, China in 1980. He holds an M.A. degree in English Language Literature from Jiangxi Normal University, China in 2008. He works for Nanchang Normal University. His area of interest includes Functional Linguistics, Discourse Analysis and English Teaching. 